\title{
Small watershed management as a tool of flood risk prevention
}

\author{
JIRI JAKUBINSKY ${ }^{1,2}$, RADKA BACOVA ${ }^{1}$, EVA SVOBODOVA ${ }^{1}$, \\ PETR KUBICEK ${ }^{1}$ \& VLADIMIR HERBER ${ }^{1}$ \\ 1 Department of Geography, Faculty of Science, Masaryk University - Kotlarska 267/2, 61137 Brno, Czech Republic \\ jakubinsky@mail.muni.cz \\ 2 Global Change Research Centre AS CR, v. v. i. - Belidla 986/4a, 60300 Brno, Czech Republic
}

\begin{abstract}
According to the International Disaster Database (CRED 2009) frequency of extreme hydrological situations on a global scale is constantly increasing. The most typical example of a natural risk in Europe is flood - there is a decrease in the number of victims, but a significant increase in economic damage. A decrease in the number of victims is caused by the application of current hydrological management that focuses its attention primarily on large rivers and elimination of the damages caused by major flood situations. The growing economic losses, however, are a manifestation of the increasing intensity of floods on small watercourses, which are usually not sufficiently taken into account by the management approaches. The research of small streams should focus both on the study of the watercourse itself, especially its ecomorphological properties, and in particular on the possibility of flood control measures and their effectiveness. An important part of society's access to sustainable development is also the evolution of knowledge about the river landscape area, which is perceived as a significant component of global environmental security and resilience, thanks to its high compensatory potential for mitigation of environmental change. The findings discussed under this contribution are based on data obtained during implementation of the project "GeoRISK" (Geo-analysis of landscape level degradation and natural risks formation), which takes into account the above approaches applied in different case studies - catchments of small streams in different parts of the Czech Republic. Our findings offer an opportunity for practical application of field research knowledge in decision making processes within the national level of current water management.
\end{abstract}

Key words flood risk; small watercourse; water management; environmental change

\section{INTRODUCTION}

Floods represent one of the most important types of natural risks that affect man and significantly influence the spatial arrangement of human activities in the landscape. The increasing frequency of extreme hydrological situations that has been observed in the long term (CRED 2009), is most often understood as a manifestation of global environmental change at the local level. In addition to frequently discussed "classic floods" on large rivers, caused by long lasting precipitations, flash floods that affect municipalities near the smaller watercourses are becoming more typical, especially for continental Europe. During the period 1950-2006 flash floods have caused $40 \%$ of the total flood damage in Europe (Barredo 2007). Even further increased frequency of flash floods can be expected in the future according to Marchi et al. (2010), caused mainly by the impact of global climate change, storm-weather systems, and river discharge conditions. Flash floods are typically tied to small-tomedium streams in the catchment area up to $1000 \mathrm{~km}^{2}$ (Gaume et al. 2009). It is therefore a phenomenon which, due to their growing extent and dynamics, especially affects locations without previous historical experience with similar events. And due to this fact, flash floods caused major damages on the properties and infrastructures concerned.

For the above reasons, it is obvious that the importance of studying runoff processes in the landscape at the local level of small catchments is constantly growing. However, it is important to take into account the broader context that includes the landscape as a whole and understands it as a complex ecosystem. The concept of ecohydrology (Zalewski et al. 1997, Zalewski 2000), which began to be addressed as a major activity under the 5th phase of the International Hydrological Programme (IHP) of UNESCO currently points out that a comprehensive study of riverine ecosystems with consideration of anthropogenic activities as an integral component of the landscape is needed. The ecohydrological paradigm is based on the assumption that the regulation of nutrients and water cycle, by synergistically integrating hydrological and biotic processes, should provide opportunities to enhance the capacity of ecosystems to absorb human impact (Zalewski 2002). Therefore the potential of current hydrological research is especially in the utilization of large 
amounts of data available in high resolution (at the sub-basin level) and their subsequent generalization, which will allow us to make general and yet sufficiently effective conclusions, reflecting the local conditions.

\section{FLOOD RISK MANAGEMENT AS A KEY FACTOR FOR DEVELOPMENT OF KNOWLEDGE ABOUT SMALL STREAMS}

Generally, disaster risk management is a continuous iterative process, which supports the decisionmaking process, planning, knowledge acquisition, and raises awareness and resilience in emergency issues. We can distinguish four successive phases (see Fig. 1). The whole cycle starts with two phases before the disaster event, in our case before the flood event - prevention and mitigation (1st phase), and preparation (2nd phase). After the disaster event we can identify response and recovery (3rd and 4th) phases. Each part of the cycle is characterised with activities performed during a specific time. Plate (2002), Kubíček et al. (2011), Kundzewicz and Matczak (2012) describe them as follows: the prevention and mitigation phase is represented by the long-term activities to reduce the risk of hypothetical flood by land-use planning and land management. These activities depend on the previous experience with natural floods, risk assessment and identification. Preparation phase occurs when we can predict imminent danger of flooding. It includes short-term activities like early warning, emergency planning and evacuation. The response and recovery phases after the flood typically include rescue services, and recovery to or close to the initial state.

In most countries of the European Union the flood risk management is distributed to many administrative platforms - from international cross-border initiatives (Horak et al. 2008), to local regional level. Obligations for member states are defined in the Directive 2007/60/EC on the assessment and management of flood risks, which is an extension of EU Water Framework Directive 2000/60/EC. Both legal frames require their implementation into national laws and a six-year planning cycle for flood risk management by 2015. All requirements are dealing with the most flood endangered areas of the country, mainly large rivers, and the hazards from small watercourses are still neglected. The issue of small streams research is discussed below.

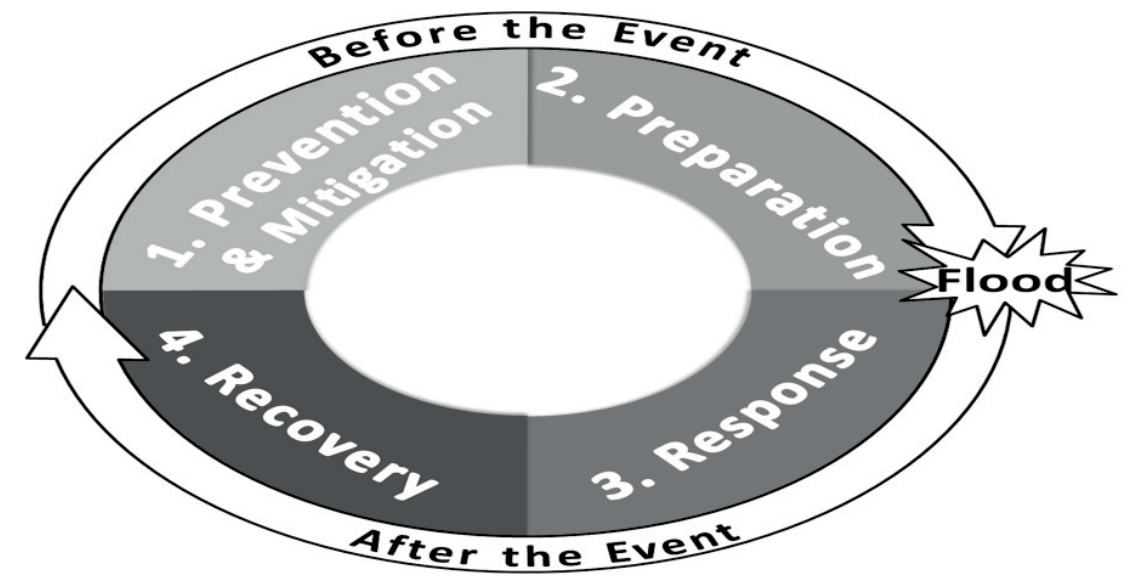

Fig. 1 Flood Risk Management Cycle (Based on Floodsite (2009), Plate (2002)).

\section{RESEARCH ON SMALL WATERCOURSES - OPPORTUNITIES AND ISSUES}

Since human society perceives river network from the view of primary economic interests, a river is traditionally seen as an element able to collect water during floods and to provide water during drought. Under optimal conditions, the river can be used as a transport corridor and sediments in the hinterland can also serve as a source of construction material. All these features are naturally fulfilled, particularly in the case of large rivers where the strengths are most apparent. For these reasons, small streams are usually of peripheral interest to society and therefore their management is still a marginal topic within the field of water management. Although the small streams (defined as all streams that are not identified as "significant") usually form most of the overall length of all 
streams in the watershed (Shreve 1969), their management is done only by farmers and land-workers that operate directly on the floodplain near the river. The approach is often limited only to hard riverbed regulation in order to get the largest area of arable land and ensure a "convenient" course of potential flood situations.

Opportunity for addressing the listed unsustainable situation regarding water management of small streams may arise from obligations associated with the adoption of the Water Framework Directive - 2000/60/EC (European Parliament, Council 2000). This document requires that the member states achieve a "good ecological status" for all water bodies, including small watercourses. However, the real fulfilment of the ecological indicator (consisting of evaluation of the biological, physico-chemical and hydromorphological quality) of all streams which are included within the River Basin Districts certainly cannot be expected. An important question therefore is to which level of detail are the fluvial ecosystems truly assessed and, in particular, whether the proposed measures to improve the current situation can ensure a sustainable good status of small streams, even taking into account the current management of the whole catchment.

The issue of small watercourses is often neglected due to several reasons - people either do not entirely understand the importance of streams within the landscape and therefore do not know all the functions which the stream could perform, or they are facing various practical and theoretical obstacles that hinder the implementation of measures to improve the current state of the stream. The solution must be sought in the overall awareness of the importance of small streams as an essential part of the landscape, which, together with the riparian zone represents a unique ecosystem. Due to its own characteristics the small river ecosystem can significantly affect the landscape matrix and the links between other landscape components. What is important is a complex, transdisciplinary view of all rivers and their hinterland, which improves the understanding of the problem -i.e. not viewint the importance of small streams from a relatively narrow perspective of various environmental disciplines. In any case, this is not to reduce the importance of the knowledge gained in terms of sub-disciplines, but to the contrary, an effective use through their synthesis, certain generalization and the subsequent presentation of more generally valid conclusions.

Some contribution to the raising awareness of the importance of small streams may be currently found in the developing concept of ecosystem services. This approach involves evaluation of a relatively broad range of services based on various functions of the landscape, which is often directly related to the presence of water bodies. For example, one of the partial documents developed under the concept of the Millennium Ecosystem Assessment (MA 2005a), which is focused on wetlands and water bodies in the landscape (MA 2005b), is working with a quite extensive list of services associated also with small streams. The identified services are divided into four main categories the provisioning, regulating, cultural and supporting services. The attempt to access the value of ecosystem services (without taking into account the accuracy and timeliness of the data) can be a good tool to highlight the existence of functions which watercourses provide to human society. It is also a suitable approach, which points to the existence of a watercourse as a sub-component of the landscape ecosystem dependent on the state of other components and on the quality of the links between them. However, the question remains as to what extent the study of ecosystem services can contribute to practical improvement of the small watercourses management - thus whether the general expression of the fluvial ecosystem value can assist in the subsequent development of initiatives to improve the quality of the current stream state.

The concept of ecosystem services valuation can probably affect the overall state of streams, especially when dealing with the issue of flood risk whose direct relationship with the environmental condition of the landscape gradually enters into the societal awareness. An example of a relatively effective water policy, which application can ultimately lead to improvement of runoff processes, is the evaluation of ecological status of watercourses under the national legislation based on the Water Framework Directive (2000/60/EC). Ensuring the implementation of this approach on all watercourses is very problematic, especially in the case of small streams - from gathering information about the streams' state, through their relevant evaluation up to the adoption of measures to improve the situation. 


\section{CASE STUDY - SMALL STREAMS RESEARCH IN THE CZECH REPUBLIC}

One of the ways to highlight the importance of small streams is carrying out research in the form of a case study which can provide suitable data to demonstrate the current state of knowledge. As an example of an appropriate study we present the results of a project focused exclusively on small streams. The project "GeoRISK: Geo-analysis of landscape level degradation and natural risks formation" is based on a transdisciplinary approach and contains basic geographical methods in geomorphology, hydrology, and cartography (Báčová et al. 2013). The main aim was to identify the most degraded areas, areas which are losing natural environmental values and especially areas which are vulnerable to flooding. This approach was applied to small watercourses in the Czech Republic, which suffer from the lack of river management and interest of municipalities. In general, the attention is directed primarily to large rivers, but there is increasing economic damage in small watercourses which are caused by a growing intensity of floods due to manifestations of environmental change. These phenomena have a retroactively negative impact on human society. Model areas (listed in Fig. 2) were chosen on the basis of their natural conditions, different human activities, and types of land use.

As a major geomorphology method an anthropogenic forms inventory was used, which consisted of the exact location of man-made landforms (e. g. mine, man-modified watercourse and polder) and man-made objects (e.g. bridge construction, sewerage network) in the river catchment. For better quantification of human impact on the landscape a weight (based on expert estimate) for each anthropogenic landform indicating the effect on the floods behaviour and a weight indicating location of anthropogenic forms within the river catchment was determined. During the detailed field survey the hydro-morphological analysis was performed and also the Channel Capacity Coefficient (CCC) was determined as a specific indicator which provides information about the potential for emergence of a flood situation. This indicator, based on several selected factors (such as riverbed material, the nature of the banks and bottom fortifications, etc.), shows the overall condition of the channel and the degradation of natural values that affect the dynamics of the runoff process.

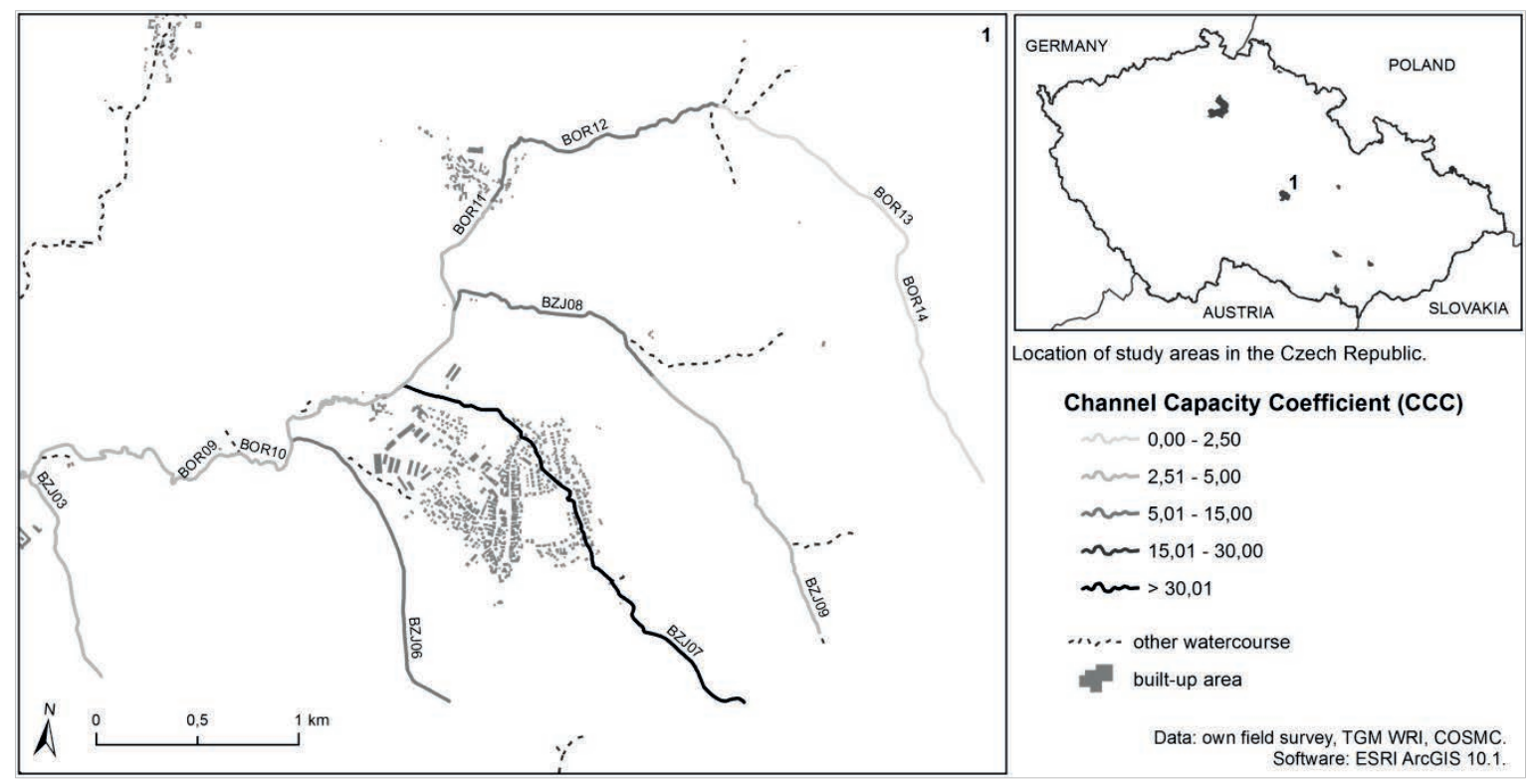

Fig. 2 Spatial variability of the CCC values within the selected section of the watercourse (the Borovsky Brook) and an overview of all interested basins in the Czech Republic.

The results of the project were cartographically processed into hexagonal mosaic maps (Báčová et al. 2013) where the level of degradation is presented by the changing colour saturation. These 
resulting maps show degraded areas influenced by anthropogenic pressure that are vulnerable to flood situations. Hexagonal mosaic maps were compared with potentially flooded areas at $\mathrm{Q}_{5}, \mathrm{Q}_{20}$ and $\mathrm{Q}_{100}$ levels (TGM WRI 2012) and the conformity of these territories was recorded in nearly $75 \%$ of the study areas. The above procedure provides relatively detailed information on sub-component (hydromorphological parameters) of the overall ecological status of a small stream and its map expression (Fig. 2) is suitable for identifying the spatial variability of the observed values. Fig. 3 gives the information about the value of the mentioned indicator (CCC) in the longitudinal profile of the Borovsky Brook, as one of the model sites. When comparing the CCC values with the size of the cross-sectional area within particular sections of monitored stream we can identify the sites that have a high or low risk of potential flooding. The accuracy of the results was also verified during recent flash floods in the model catchment.

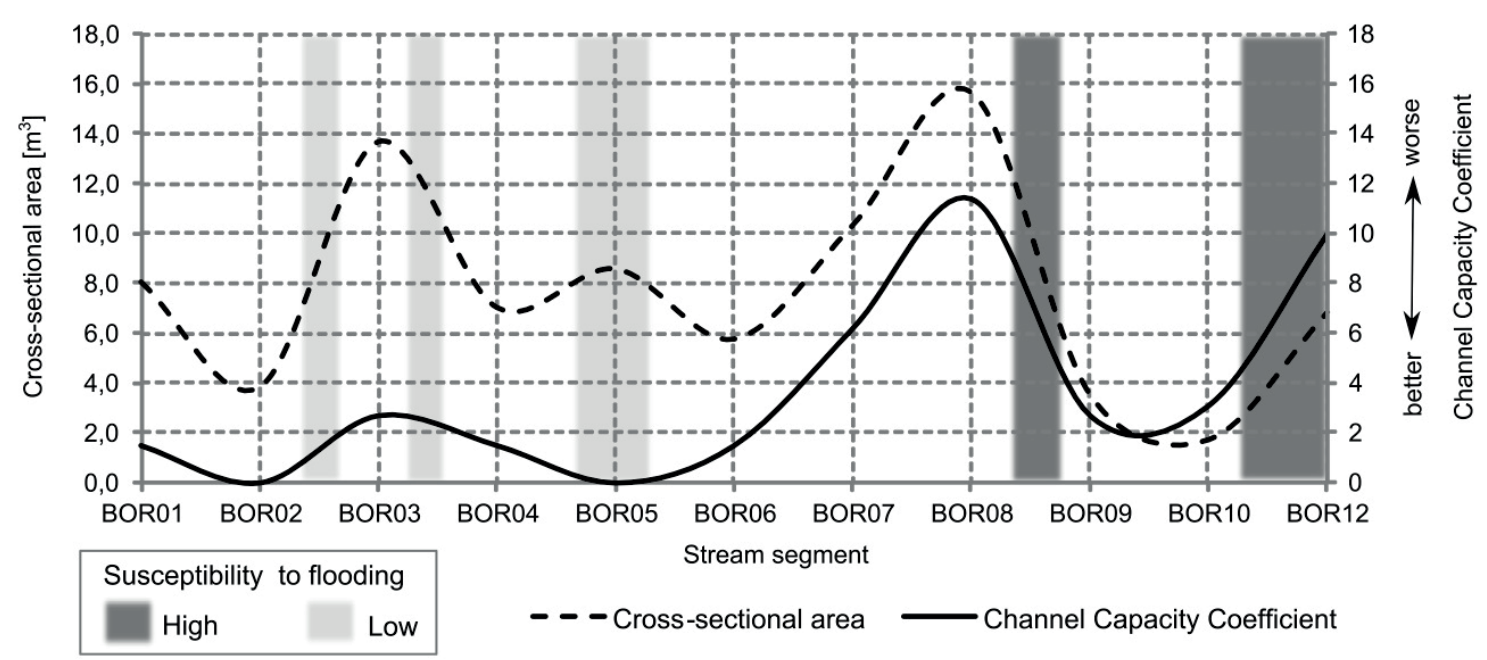

Fig. 3 Possible way to identify the risk locations within a small stream catchment.

\section{CONCLUSION}

Even though the small watercourses and their surroundings represent often unique and irreplaceable ecosystems from the perspective of a number of scientific disciplines, the biggest problem remains in their social perception. Humans especially strongly perceive only the local character of small streams (the extent of area influenced by stream is seemingly very small), which causes the perceived insignificance of these landscape components for common decision-making level (usually the spatial equivalent of catchment of the 1st order stream). The approach to the small stream management is demonstrated for example by the fact that there is practically no clear definition or consensus of what constitutes a "small watercourse" (Moore \& Richardson 2003). A network of small streams plays a crucial role in shaping the character of runoff processes - besides the reduction of extreme hydrological conditions (floods, drought periods) the potential can also be seen in affecting the biological and physico-chemical values of the entire river system.

In the future, it is necessary to develop further initiatives - both at the decision-making (legislative) level and on the theoretical level (by spreading awareness about the functioning of fluvial ecosystems), which would allow for a more effective approach to the small stream management. Benefits can be expected, especially from the development of new paradigms throughout participating disciplines which would come from solving individual scientific problems, but for their application the state of the river landscape as a whole would need to be addressed - e.g. the Declaration on Sustainable Floodplain Management (ERCE 2008), which sees further development in the harmonization of three dynamic and evolving components: catchments, water resources and society.

Generally, watercourses together with the floodplains are the ecosystems that are particularly exposed to high anthropogenic stress (Meybeck 2003). The specific impacts of human activity can 
be studied from many different points of view - one of the possibilities is also the case study presented within this contribution, which especially focuses on the issue of morphological parameters of small streams, as one of the environmental indicators. Based on similar approaches applied to selected topics related to the issue of small streams, it is appropriate to address the question of sustainable development of the floodplain as an area in which a large number of human activities are concentrated and its security is therefore absolutely crucial for the overall quality of life. Expression of the environmental status of the watercourse and its riparian zone on the basis of selected ecological indicators can be regarded as a key approach which may provide a comprehensive view on the issue of flood risk on small streams.

Acknowledgements The authors are grateful for the support of the internal project (specific research) of Masaryk University - MUNI/A/0952/2013.

\section{REFERENCES}

Báčová, R., et al. (2013) Geo-analysis of Landscape Level Degradation and Natural Risk Formation under Uncertainty. IFIP Advances in Information and Communication Technology 413, 285-293, doi: 10.1007/978-3-642-41151-9 27.

Barredo, J. I. (2007) Major flood disasters in Europe: 1950-2005. Natural Hazards 42(1), 125-148, doi: 10.1007/s11069-0069065-2.

CRED (2009) The International Disaster Database. Centre for Research on the Epidemiology of Disasters. Available from: http://www.emdat.be/ (accessed 28 October 2013).

ERCE (2008) Declaration on Sustainable Floodplain Management - change of perspective. European Regional Centre for Ecohydrology under the auspices of UNESCO, Int. Inst. Polish Academy of Sciences.

European Parliament, Council (2000) Directive 2000/60/EC of the European Parliament and of the Council of 23 October 2000 establishing a framework for Community action in the field of water policy. Official Journal of the European Communities.

Floodsite (2009) Integrated Flood Risk Analysis and Management Methodologies. FLOODsite Consortium. Available from: http://www.floodsite.net/default.htm (accessed 12 October 2013)

Gaume, E., et al. (2009) A compilation of data on European flash floods. J. Hydrol. 367(1-2), 70-78.

Horak, J., Orlik, A. and Stromsky, J. (2008) Web services for distributed and interoperable hydro-information systems. Hydrol. Earth Syst. Sci. 12, 635-644.

Kubíček, P., et al. (2011) Flood Management and Geoinformation Support within the Emergency Cycle (EU Example). In: Environmental Software Systems. Frameworks of eEnvironment, 77-86. Springer.

Kundzewicz, Z. W. and Matczak, P. (2012) Natural risks: mitigation and adaptation. Ecohydrology \& Hydrobiology 12(1), 3-8, doi: 10.2478/v10104-012-0005-3.

MA (2005a) Millennium Ecosystem Assessment Synthesis Report. World Resources Institute.

MA (2005b) Ecosystems and Human Well-Being: Wetlands and Water. Synthesis. World Resources Institute.

Marchi, L., et al. (2010) Characterisation of selected extreme flash floods in Europe and implications for flood risk management. J. Hydrol. 394, 118-133.

Meybeck, M. (2003) Global analysis of river systems: form Earth system controls to Anthropocene syndromes. Philosophical Transactions of the Royal Society of London B 358(1440), 1935-1955.

Moore, R. D. and Richardson, J. S. (2003) Progress towards understanding the structure, function, and ecological significance of small stream channels and their riparian zones. Can. J. For. Res. 33, 1349-1351.

Plate, E. J. (2002) Flood risk and flood management. J. Hydrol. 267, 2-11.

Shreve, R. L. (1969) Stream lengths and basin area in topographically random channel networks. J. Geol. 77, 397-414.

TGM WRI (2012) Digital water management database (DIBAVOD). T. G. Masaryk Water Research Institute, public research institution. Available from: http://www.dibavod.cz/ (10 November 2013).

Zalewski, M. (2000) Ecohydrology - the scientific background to use ecosystem properties as management tools toward sustainability of water resources. Guest Editorial. Ecological Engineering 16, 1-8.

Zalewski, M. (2002) Ecohydrology - the use of ecological and hydrological processes for sustainable management of water resources. Hydrol. Sci. J. 47, 825-834.

Zalewski, M., Janauer, G. A. and Jolankai, G. (1997) A new paradigm for the sustainable use of aquatic resources. UNESCO IHP Technical Document in Hydrology No. 7; IHP - V Projects 2.3/2.4. UNESCO. 